\title{
Employee Motivation Incentives and Their impact on The Organization's Productivity
}

\author{
Article by Jacqueline Aziri \\ PhD in Management, Texila American University \\ E-mail: koyaki07@gmail.com
}

\begin{abstract}
This article presents literature on employee motivation incentives and evaluates their impact on organizational productivity. The article aims at explicitly highlighting the effect of incentives on different elements that influence organizational productivity. A qualitative analysis of literature was employed to consolidate literature that informed the study. The findings indicate that incentivizing the organization's activities undertaken by human resources helps in improving organizational productivity. The results showed that incentives increase productivity by enhancing the following elements; employee work performance, employee engagement, innovation and creativity, organizational commitment and job satisfaction. This finding will provide useful information to organizations when designing incentive schemes and analysing their functions and general impact.
\end{abstract}

Keywords: Employee motivation, incentives, organizational productivity, motivators.

\section{Introduction}

Improvement of organizational productivity is one of the principal functions of the top management in any institution. Radically, organizational productivity is enhanced and determined by a variety of elements such as; corporate culture, communications, systems and tools, training and development, motivation and incentives, planning and programmes, control and reporting, staffing, structure, process, strategy, goals and objectives (Cording et al., 2014). However, a growing body of literature suggests that employee motivation is fundamental (Becker et al., 2018).

Contemporarily, the focus on employees has increased due to the fact the different trends such as globalization, automation, organizational culture changes have become rampant. Such changes have also altered characteristics of employees; hence, organizations ought to adapt their human resource management strategies (Caliskan \& Isik, 2016). One of the critical facets of contemporary adaptation is employee motivation. Motivation is undertaken to ensure the commitment of human resources and other members is enduring. As a human psychological trait, motivation influences the level of engagement in a person's behaviours (Hennessey et al., 2015). In general, motivation involves imparting on individuals in a way that the impact can act as a primer to exceptional performances. Employee motivation encourages individuals to adopt purposive behaviours and have the desire to put in an effort and achieve specific goals and objectives. This level of motivation, a variety of dynamic factors are considered as well as an appreciation of different theories of motivation.

Motivation refers to the force that encourages individuals to garner their objectives. The concept can be extrinsic where motivations are harnessed from outside the person or intrinsic where motivation is derived from the person instead of external influence. The positive results associated with motivation have led organizations to continuously sought to motivate their employees and in tandem, increase their productivity. Lack of employee motivation can dictate the failure of an organization; thus, it is imperative for organizations to devise new methods of employee motivation depending on employee characteristics. If suitable arrangements are used, productivity generally increases, and when different strategies are employed, negative results such as high employee turnover and low performances are witnessed (Deci and Ryan, 2014). From this perspective, this research will seek to evaluate employee motivation Incentives and their impact on the organization's productivity. 


\section{Definition of employee motivation}

There is no standard definition of employee motivation. Naile \& Selesho (2014), define employee motivation as imparting purposeful behaviours that can propel employees towards the primary goals of the organization. Lazaroiu (2015), defines employee motivation as the provision of the steering force to employees so that they can pursue professional and organizational goals and objectives.

\section{Reasons for employee motivation}

Homberg et al. (2015), posit that organizations engage in employee motivation to enhance job satisfaction because of the lack or presence of motivation influences satisfaction. Job satisfaction is an essential facet in employee motivation as it affects the quality of work and the willingness to work. Fernandez \& Moldogaziev (2015) argue that job satisfaction is pegged on the capability of individuals to benefit from specific motivators such as recognition, promotion, personal growth, and success. Hence, employee motivation is undertaken to improve job satisfaction. Employee motivation is employed to increase employee loyalty. Iqbal et al. (2015) explain loyalty itself is an example of commitment where employees are willing to sacrifice their self-interests and further the company's objectives. Thus, employee motivation strategies are used to demonstrate that mutually beneficial partnership is being adhered to whereby employee's sacrifices are dully recognized and compensated. Organizational commitment is also a fundamental element that provides an impetus for employee motivation. This commitment is commonly fostered through rewards in that "the rewards one receives from an organization and the experience one has while achieving the reward impacts the extent of the attachment an employee has toward an organization" (Smith, 2015). Employee motivation is vital in augmenting the willingness to remain at a particular institution and desire to achieve its goals.

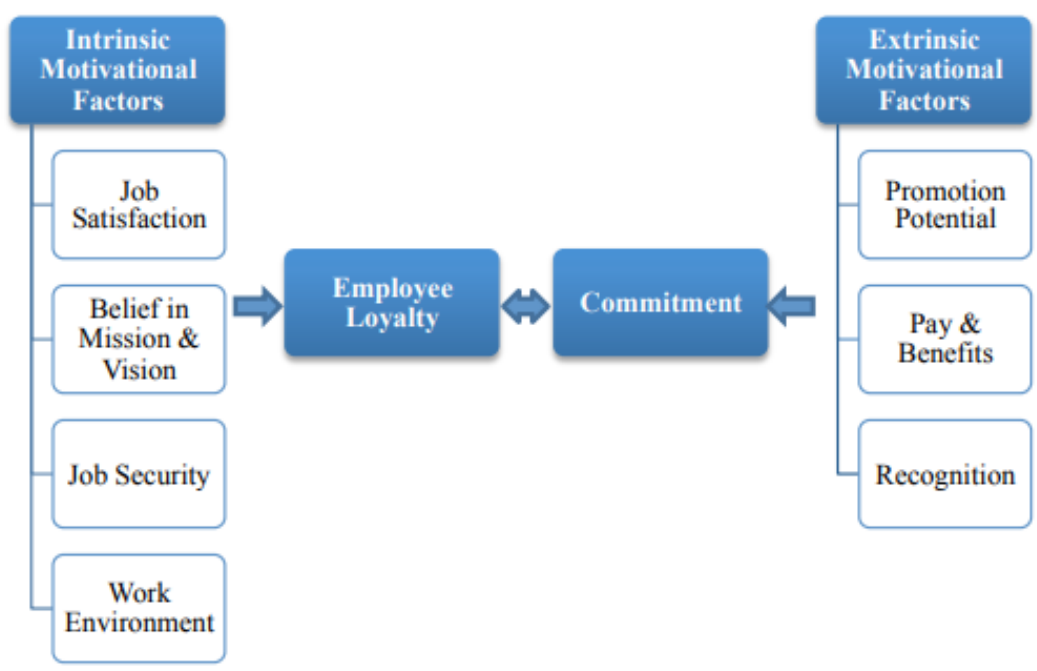

Figure 1. The interaction between intrinsic and extrinsic motivators with employee loyalty and commitment, adapted from, Smith (2015)

The need to achieve organizational goals also underpins the need for employee motivation since motivated employees have the desire to garner these goals. Furthermore, employee satisfaction and promoting a healthy human resource is identified as an important reason to motivate employees. Most organizations use incentives to foster physically and mentally healthy workforce by catering for their psychological needs. Employee motivation is used to provide socialization and promote the tenets of teamwork and collaboration at the workplace. Additionally, employee motivation is employed to recognize the inputs and achievements of human resource as a method of satisfying their esteem needs. Lastly, the practice is used to guarantee the financial security of employees. 


\section{Incentives and types of incentives}

Faisal et al. (2015), define incentives as things that motivate a person to undertake specific actions whether through cooperation or as an individual. There are different types of incentives employed in workplaces to motivate employees. These are;

\section{Offering incentive plans}

These plans are used to motivate employees through mutual benefits. It takes different forms depending on its suitability as an organization. Firstly, bonus pay is typically employed to encourage employees in production; marketing and sales professions where the organization offers bonuses after predetermined goals are achieved. Performance units are incentive plans where the top management is rewarded after the company achieved predetermined financial milestones. Thirdly, Poole (2017), advances that profit-sharing incentive plan is also used to motivate employees. In such programs, pretaxed profits are distributed among employees depending on set parameters such as position held within the organization, longevity of the employee at the organization, performance metrics and amount of services delivered. Lastly, the incentive plan can offer stock options to workers that wish to invest in the organization.

\section{Financial rewards}

Money is a primary element in addressing social/security and physiological needs. Hence, financial incentives are given to employees as rewards for handwork and instil the motivation to achieve more. These incentives are offered through the provision of cash prizes to employees to motivate them to achieve specific goals or reward them for making such goals. These incentives are calculated as percentages of sales closed or can be fixed amounts. They have actualized through organizations bonus-programs or profit sharing. The financial rewards can also come in the form of spot bonuses. They are commonly used to reward aspects such as teamwork, regular attendance, innovation, service excellence, and job performance. Another strategy involves offering pay and benefits to employees to encourage employee loyalty and commitment. However, Garbers \& Konradt (2014), argue that employee motivation is achievable through the use of monetary rewards under certain levels although extended use can potentially erode teamwork and cohesiveness. Additionally, financial incentives are limited in efficacy when job dissatisfaction in evident or when employees are self-actualized. Hence, incorporation of nonfinancial incentives is essential.

\section{Non-financial incentives}

The human resources are the most valuable resource in an organization; hence, motivating them towards personal and organizational goals is essential. For an organization to encourage employees, non-cash-based incentives are employed in the creation of value to the worker. Firstly, organizations can provide, work environment that is diverse, inclusive, safe and productive for workers such that job satisfaction levels are high. Creation of a positive atmosphere at work helps in fostering knowledge sharing, eliminations of conflict, setting goals and soliciting employee input; these elements are vital in enhancing employee motivation.

Employee motivation is also enhanced through recognition and rewarding of employees for their achievements by honouring them publicly and encouraging their contributions towards the company. According to Shaw \& Gupta (2015), praising employees and recognizing them helps in fostering enjoyable working environments; this helps in inspiring employees towards achieving and creating value for the company. Rewards and recognition are also essential in employee motivation as it enhances initiative, creativity, and innovativeness in employees. Employee motivation is increased by elevating the promotion potential of employees through constant feedback, provision of training and development opportunities, helping employees fulfil career goals and keeping them informed about the company. Job enrichment to add more challenges, scope and responsibilities motivate employees as they seek to accomplish their own career goals. Furthermore, employee empowerment and autonomy are essential motivators given that it inspires the acquisition of positive skills and confidence in subordinates. 


\section{Team incentives}

These are incentives offered to teams when they complete team initiatives. The incentives are afforded to groups relative to their performance and predetermined performance goals. However, Babcock et al., (2015) argue that such incentives lead to uneven workload distribution and limit healthy competition among employees as recognition and reward of top performers is forgone, and teamwork is prioritized.

\section{Impact of incentives on organization productivity}

Incentives are essential in instituting higher employee engagement which is significant in augmenting organizational productivity (Saks \& Gruman, 2014). Fundamentally, engaged employees are characterized by their willingness to protect the interests of the organization as well as an enthusiasm to work. The concept of employee engagement is covered under behavioural, emotional and cognitive perspectives which are similarly exploited by incentives. Higher organizational productivity is achieved by curing employee disengagement stemming from issues such as; negative organization culture, poor management, lack of upward mobility jobs, lack of engaging jobs, limited employee benefits, inadequate salaries, the strain on mental well-being and poor working conditions. Long-term employee engagement which is related to increased organizational productivity is attained by injecting incentives in HR management. Targeted benefits and rewards such as profit-sharing, work environment improvement, flexible scheduling, training, and development are promulgated to improve employee engagement which translates to increased organizational productivity.

Innovation and creativity are important in increasing organizational performance and productivity. As such, irrespective of the type of change, whether, it is corporate, technological, process or product innovation will positively impact on the productivity of the company. This innovation and creativity are commonly driven by implementing incentives for innovation. Incentivising innovation aspects such as collaboration and teamwork help in increasing organizational productivity as a result of an increased change. For instance, the incentive of recognition has been highlighted as an essential element in the establishment and sustaining a productive innovation community which translates to increased productivity. Additionally, increased productivity emanating from innovation is underpinned by the incentive of creating an appropriate working environment that facilitates development and exploitation of intellectual property. Furthermore, Faisal et al., (2015) advance that organizational productivity is achieved through incentive fuelled innovation by reinforcing creativity through performance related incentives and rewarding macro-innovation.

According to Lee \& Steers (2017), organizational commitment is an essential element in increasing organizational productivity. Organizational commitment is defined as, "the Emotional attachment that an employee felt for an Organization to adopts characteristics or perspective of the organization" (Khan et al., 2016). To achieve this commitment, offering intrinsic and extrinsic incentives to employees is fundamentals. Organization productivity increases by minimizing negative aspects of HR such as turnover, absenteeism, lateness, withdrawal behaviour and resistance to change by using incentives to instill organizational commitment. Additionally, organizational commitment achieved through incentives improves organizational productivity by augmenting employee job performance, employee engagement, job satisfaction, and employee welfare.

A study conducted by Imran et al. (2015) showed that organizational productivity correlates with job satisfaction which is harnessed from incentives. Ali et al. (2016) advance that incentives such as profit sharing and performance-related pay routinely increase job satisfaction among employees. This feeling of happiness emanating from incentives is derived from higher worker optimism and rewarding environments which are associated with high organizational productivity. As such, Edwards (2016) advances that, increased job satisfaction is directly correlated to $6.6 \%$ increase of organizational productivity while a study conducted the University of Warwick indicated that jobs satisfaction accounts for $12 \%$ increase in organizational productivity. These increases in productivity are induced by incentives which increase the dedication to work, the drive to succeed and improve in creativity. 
According to Oswald et al. (2015), the use of performance related-pays (PRP) as an incentive increases the intensity of work in the workplace. A research study conducted by (Lucifora, 2015), indicates that performance-related incentives increase the labour productivity of employees by $5 \%$ and organizational productivity by $9 \%$ by stimulating employees to work optimally and influencing the recruitment process to highly talented employees. Additionally, these incentives increase productivity as employees view PRP as positive and reasonable trade-offs that require them to contribute towards the institution's success. Apart from this, organizational productivity is increased by incentives due to selective employee sorting where high-productivity workers are selected, hired and retained. Lastly, PRP incentives that are underpinned by an equitable distribution mechanism increases organizational productivity by enhancing trust in management, organizational commitment, and job satisfaction.

However, it is imperative to note that incentives can lead to poor performance in an organization. Garbers \& Konradt (2014), argue that the use of incentives leads to stress, overwork, complaints on the distribution of pay and contentious behaviours. For instance, the use of financial incentives to award individuals in a team may lead to individualism and increased competition as employees seek individual recognition and reward; this precedent affects employee well-being, collaboration as well as limiting organizational productivity. Reduced productivity is associated with employees working to further their course as well as leading to a lack of trust in the management in cases where profitrelated incentives are used; this reduces the productivity of an organization.

\section{Conclusion}

The objective of this article has been to evaluate the subject of incentives and assess its impact on organizational productivity. Fundamentally, there are different forms of incentives such as; financial and non-financial incentives, intrinsic and extrinsic incentives and individual or team incentives. Application of these incentives generates various effects with increased organization productivity being a necessary result of incentivizing the workplace. From the analysis, it is shown that incentives improve organizational productivity by impacting positively on the critical determinants of organizational performance. The determinants impacted upon by incentives to increase organizational productivity are; employee work performance, employee engagement, innovation and creativity, organizational commitment and job satisfaction. Leveraging these determinants and augmenting them with incentives leads to increased organizational productivity. However, literature has given caveats on the use of incentives because it can lead to individualism, entitlement to financial rewards and poor motivation of employees during recessions. In general, offering incentives to human resources is vital in improving organizational productivity. Hence, the organization ought to leverage the plethora of incentive schemes and strategies as an option of boosting productivity.

\section{References}

[1].Ali, S.A.E.Z., Afridi, M., Shafi, M., Munawar, H. and Alvi, M., 2016. Impact of Tangible or Intangible incentives on job satisfaction among workers. International Journal of Management Excellence, 7(3), pp.841845.

[2].Becker, T.E., Kernan, M.C., Clark, K.D. and Klein, H.J., 2018. Dual commitments to organizations and professions: Different motivational pathways to productivity. Journal of Management, 44(3), pp.1202-1225.

[3].Babcock, P., Bedard, K., Charness, G., Hartman, J. and Royer, H., 2015. Letting down the team? Social effects of team incentives. Journal of the European Economic Association, 13(5), pp.841-870.

[4].Caliskan, S. and Isik, I., 2016. Are you ready for the global change? Multicultural personality and readiness for organizational change. Journal of Organizational Change Management, 29(3), pp.404-423.

[5].Cording, M., Harrison, J.S., Hoskisson, R.E. and Jonsen, K., 2014. Walking the talk: A multistakeholder exploration of organizational authenticity, employee productivity, and post-merger performance. Academy of Management Perspectives, 28(1), pp.38-56.

[6].Edwards, S., 2016. Examining the Relationship Between Workplace Satisfaction and Productivity. [Online] Available at: HYPERLINK "https://www.inc.com/samuel-edwards/examining-the-relationship-betweenworkplace-satisfaction-and-productivity.html" https://www.inc.com/samuel-edwards/examining-therelationship-between-workplace-satisfaction-and-productivity.html [Accessed 30 October 2018]. 
[7].Faisal Ahammad, M., Mook Lee, S., Malul, M. and Shoham, A., 2015. Behavioral ambidexterity: The impact of incentive schemes on productivity, motivation, and performance of employees in commercial banks. Human Resource Management, 54(S1), pp.s45-s62.

[8].Fernandez, S. and Moldogaziev, T., 2015. Employee empowerment and job satisfaction in the US Federal Bureaucracy: A self-determination theory perspective. The American review of public administration, 45(4), pp.375-401.

[9].Garbers, Y. and Konradt, U., 2014. The effect of financial incentives on performance: A quantitative review of individual and team-based financial incentives. Journal of occupational and organizational psychology, 87(1), pp.102-137.

[10]. Hennessey, B., Moran, S., Altringer, B. and Amabile, T.M., 2015. Extrinsic and intrinsic motivation. Wiley encyclopedia of management, pp.1-4.

[11]. Homberg, F., McCarthy, D. and Tabvuma, V., 2015. A meta-analysis of the relationship between public service motivation and job satisfaction. Public Administration Review, 75(5), pp.711-722.

[12]. Imran, R., Majeed, M. and Ayub, A., 2015. Impact of organizational justice, job security and job satisfaction on organizational productivity. Journal of Economics, Business and Management, 3(9), pp.840-845.

[13]. Iqbal, A., Tufail, M.S. and Lodhi, R., 2015. Employee loyalty and organizational commitment in Pakistani organizations. Global Journal of Human Resource Management, 3(1), pp.1-11.

[14]. Khan, M., Tarif, A. \& Zubair, S.S., 2016. Non-Financial Incentive System and Organizational Commitment: An Empirical Investigation.

[15]. Lucifora, C., 2015. Performance-related pay and labor productivity. IZA World of Labor.

[16]. Lazaroiu, G., 2015. Employee motivation and job performance. Linguistic and Philosophical Investigations, 14, p.97.

[17]. Lee, T.W. and Steers, R.M., 2017. Facilitating effective performance appraisals: The role of employee commitment and organizational climate. In Performance measurement and theory (pp. 75-93). Routledge.

[18]. Naile, I. and Selesho, J.M., 2014. The role of leadership in employee motivation. Mediterranean Journal of Social Sciences, 5(3), p.175.

[19]. Oswald, A.J., Proto, E. and Sgroi, D., 2015. Happiness and productivity. Journal of Labor Economics, 33(4), pp.789-822.

[20]. Poole, M., 2017. The origins of economic democracy: Profit sharing and employee shareholding schemes. Routledge.

[21]. Saks, A.M. and Gruman, J.A., 2014. What do we really know about employee engagement? Human Resource Development Quarterly, 25(2), pp.155-182.

[22]. Shaw, J.D. and Gupta, N., 2015. Let the evidence speak again! Financial incentives are more effective than we thought. Human Resource Management Journal, 25(3), pp.281-293. 